Article

\title{
Numerical Simulation of Knock Combustion in a Downsizing Turbocharged Gasoline Direct Injection Engine
}

\author{
Xi Wang ${ }^{1, *}$, Xun Zhang ${ }^{2}$, Minfei Wang ${ }^{2}$, Yue Han ${ }^{3}$ and Hanyu Chen ${ }^{2, *}$ \\ 1 School of Physical Education, Jianghan University, Wuhan 430056, China \\ 2 School of Energy and Power Engineering, Wuhan University of Technology, Wuhan 430063, China; \\ 99412483@qq.com (X.Z.); 516704594@qq.com (M.W.) \\ 3 Dingcheng Machinery Manufacturing Co., Ltd., Sihong Economic and Technological Development Zone, \\ Sihong 223900, China; 1403355769@qq.com \\ * Correspondence: wangxi050611024@126.com (X.W.); chyu@whut.edu.cn (H.C.); Tel.: +86-151-7245-3129 (X.W.); \\ +86-188-2735-6249 (H.C.)
}

Received: 30 August 2019; Accepted: 30 September 2019; Published: 2 October 2019

\begin{abstract}
Engine knock has become the prime barrier to significantly improve power density and efficiency of the engines. To further look into the essence of the abnormal combustion, this work studies the working processes of normal combustion and knock combustion under practical engine operating conditions using a three-dimensional computation fluid dynamics (CFD) fluid software CONVERGE (Version 2.3.0, Convergent Science, Inc., Madison, USA). The results show that the tumble in the cylinder is gradually formed with the increase of the valve lift, enhances in the compression stroke and finally is broken due to the extrusion of the piston. The fuel droplets gradually evaporate and move to the intake side under the turbulent and high temperature in the cylinder. During the normal combustion process, the flame propagates faster on the intake side and it facilitates mixture in cylinder combustion. During the knock combustion simulation, the hotspots near the exhaust valve are observed, and the propagating detonation wave caused by multiple hotspots auto-ignition indicates significant effects on knock intensity of in-cylinder pressure.
\end{abstract}

Keywords: supercharged gasoline direct injection engines; knock; working process; numerical simulation

\section{Introduction}

High boost and fuel direct injection possess the potential of enhancing power density and fuel economy in downsized spark ignition (SI) engines running under high load conditions. However, high loads also induce more harsh thermodynamic conditions in the cylinder, which promote the occurrence of the typical abnormal combustion phenomena such as the conventional knock even super-knock [1,2]. $\mathrm{Yu}$ et al. reported that engine knock is related to auto-ignition of end gas [3]. In previous research, engine knock occurred owning to detonation [4]. In the recent decade, the development of high boost and direct injection in gasoline engines under low engine speed and high load operating conditions, nevertheless, has been threatened by the occurrence of a new abnormal combustion, namely super-knock or deto-knock [5,6]. The peak pressure in the cylinder can exceed $30 \mathrm{MPa}$ and the pressure oscillation amplitude can exceed $20 \mathrm{MPa}$, which is extremely destructive and it can cause spark plug breakage, valve blowout, or piston ablation [5,7]. The super-knock mechanism is remarkably different from that of the conventional knock, showing that it occurs owing to a different combustion mode in the cylinder. In the literature [8-10], a number of researches on end-gas autoignition because it is relevant to engine knock or super-knock. Mittal et al. [8] studied the influencing factors of the starting point of the knock from a single-cylinder gasoline engine. During the experiment, it is 
found that the auto-ignition of the end-mixture already appeared in several cycles before the knock occurred. Marseglia et al. [9] investigated the effects of different fuel injection strategies on the fuel-air blending in the cylinder and the corresponding combustion processes in a gasoline engine. AVL FIRE simulations are conducted to study the turbulent flow in cylinder and to evaluate the different mixture formation on flame propagation. Robert et al. [10] used precise LES (large eddy simulation) codes and modified ECFM-LES (extended coherent flame model-LES) and TKI (tabulated kinetics of ignition) models to predict in-cylinder pressure oscillation, frequency of knock occurrence and the corresponding crank angle at the different ignition timing strategies. It was found through three-dimensional analysis that the knock occurred at a random position, but mainly on the side of the exhaust valve.

In addition, some issues represent that the abnormal combustion such as super-knock is closely relevant to the auto-ignition of the mixture before spark ignition, also known as pre-ignition, and it possesses sporadic and transient characteristics [5,11-13]. However, the understanding of auto-ignition is not clear enough, and the mechanism for the occurrence of super-knock is not yet distinct. Wang et al. [14] adopted a visualized rapid compression machines (RCM) to study the relationship between the pre-ignition and super-knock, and found that the early start of the hotspot may cause a conventional knock instead of a super-knock. The most important difference between a super-knock and conventional knock is the amplitude of the pressure rise at the start of the pressure oscillation. In addition, a conventional knock continuously occurs because the spark-triggered flame propagation compresses the end unburned gas to auto-ignition. Nevertheless, the super-knock is an occasional event and the combustion starts prior to spark timing. If the hotspot starts later, most of the combustible mixture has already been burned and the pressure rises less, then the knock or super-knock will not be triggered. Okada et al. [15] used visible methods to directly observe the pre-ignition caused by solid particles. There was a large amount of floating particles in the cylinder after pre-ignition and these floating particles caused the next premature combustion. They proposed a possible mechanism of pre-ignition caused by sediments: That is, the floating particulates formed after the sediment fall off will burn in the normal combustion cycle; after that, although the flame on the particle surface is extinguished during the gas exchange process, the chemical reaction on the surface continues, which can allow the particles to maintain a certain temperature. Then, during the compression stroke, for the reason of the temperature and pressure of the ambient mixture rising, the chemical reaction on the particle surface accelerates and ignites the surrounding mixture, resulting in a pre-ignition. Dahnz et al. [16,17] used endoscopic optics to observe the spatial position of the pre-ignition point in the cylinder at the moment of super-knock. It was found that the pre-ignition point was widely distributed along the plane of the cylinder gasket and that super-knock is not induced by structural hot spots such as sparking plugs. In their experiments, it was found that the use of three kinds of lubricating oil sold in the market induced the abnormal combustion such as pre-ignition, indicating that the pre-ignition and super-knock caused by lubricating oil were not incidental. Kalghatgi et al. [18] cited the hotspot self-ignition theory and concluded that detonation may occur within a hot spot in the event of super-knock. The unburned mixture can react chemically in a short time and in a small space with rapid exothermic after shock compression. The released energy in turn supports the propagation of the precursor shock. Due to the strong coupling of this precursor shock and chemical reaction, detonation combustion can reach extremely high pressure peaks, and a super-knock is more likely to be the result of the mutually reinforcing 'developmental detonation' generated by multiple hotspots.

From the literatures mentioned above, it can be seen that pre-ignition and super-knock are utilized to represent the engine knock occurred at low speed and high load operation conditions of the engines. Pre-ignition indicates the combustion of the fuel-air mixture triggered by hot-spots in cylinder other than spark ignition prior to the spark timing. Researchers usually distinguished the distinction between pre-ignition and super-knock by experimental investigation and numerical simulation. A numerous experiments to characterize the super-knock combustion process have been carried out including optical engine and rapid compression machine $[4,5,9,12,13,17]$. In addition, computation 
fluid dynamics (CFD) has been widely used to study the abnormal combustion in the gasoline engines [10,11,19-21]. Shao et al. [20] adopted KIVA-3V code and Chemkin to conduct engine simulation and chemical kinetics investigations of the effects on ignition delay time and flame speed. Teraji et al. [21] used STAR-CD to investigate the interaction between in-cylinder flow conditions and flame propagation, and tumble and swirl flows were produced in cylinder by inserting various baffle plates in the middle of the intake port. Nevertheless, there are few literatures concentrating on the formation mechanism of a super-knock under the practical engine operating conditions. The existing studies focus on optical engines, visualization constant-volume devices and numerical simulation carried out to investigate the end-gas auto-ignition under approximate engine operating conditions. There are still gaps between the above mentioned studies and the end-gas autoignition of the gasoline engines in service under practical engine conditions. Simultaneously, the end-gas autoignition process by means of the multi-dimensional simulations can fully represent the knock phenomena compared to 1D simulations. 3D simulation takes into account the essential factors such as turbulence, wall heat transfer and boundary layer, which play significant roles in an engine knock. Furthermore, temperature inhomogeneity in the gasoline engines in service should be also considered and the initial temperature and pressure, domain dimension taken into account in further studies are prototypic of a gasoline engine.

Due to the above mentioned motivations, this study investigated the end-gas autoignition in a production engine adopting 3D numerical simulation coupled with the detailed chemical mechanism of the combustion of engines. The working process of a 4-cylinder turbocharged gasoline direct injection engine was modeled and end-gas autoignition and flame propagation were investigated under practical engine operating conditions, respectively. The objectives of the current numerical simulation study were to further identify the locations of end-gas autoignition and to comprehend the formation mechanism of knock occurrence in practice.

\section{Methodology and Model Descriptions}

\subsection{Methodology}

In this study, a SAGE computation solver in CONVERGE (Version 2.3.0, Convergent Science, Inc., Madison, WI, USA) codes was selected in order to predict the autoignition controlled by reaction kinetics in a gasoline engine [22,23]. In addition, a detailed chemical reaction mechanism coupled with the algorithm of adaptive mesh refinement (AMR) was adopted to characterize the multiple combustion regimes such as ignition, premixed and diffusion combustion process.

As illustrated by Turns [24], a multi-step chemical reaction mechanism of the combustion is described as follows:

$$
\sum_{i=1}^{M} v_{i, r}^{\prime} X_{i}=\sum_{i=1}^{M} v_{i, r}^{\prime \prime} X_{i}, \quad r=1,2, \ldots, R
$$

where $v_{i, r}^{\prime}$ and $v_{i, r}^{\prime \prime}$ are the stoichiometric coefficients for reactants and products, respectively, for species $i$ and reaction $r, R$ is the total number of reactions and $X_{i}$ indicates the corresponding species $i$.

The equations of energy conservation and mass are solved for a specified computational cell as follows:

$$
\begin{gathered}
\frac{d\left[X_{i}\right]}{d t}=\dot{\omega}_{i} \\
\frac{d T}{d t}=\frac{V \frac{d P}{d t}-\sum_{m}\left(h_{i} \dot{\omega}_{i}\right)}{\sum_{m}\left(\left[X_{m}\right] \bar{c}_{p, i}\right)}
\end{gathered}
$$

where $V$ indicates volume, $P$ pressure, $T$ temperature and $\dot{\omega}_{i}$ net reaction rate of the specified species $i$. The $h_{i}$ and $\bar{c}_{p, i}$ represent the molar specific enthalpy and molar constant-pressure specific heat, respectively. 
In this study, a standard RNG (renormalization group) closure model and an improved two equation eddy viscosity turbulence model based on a generalized RNG closure were adopted in CONVERGE software, respectively. By averaging the equations of motion over infinitesimal bands of small scales and collecting the effect of the scale removal process in a modified viscosity, the RNG method removes the impact of smaller scale structures on the larger ones. This approach has been used to derive the $k$ and $\varepsilon$ equation from the N-S (Navier-Stokes) equations, including providing numerical values for the model constants in the transport equations [25]. In addition, a generalized RNG turbulence model based on the local 'dimensionality' of the flow field is also adopted and the detailed description is illustrated in literature [26]. Compared with the standard $k-\varepsilon$ model, the $k$-equation remains the same in the RNG version. Nevertheless, an extra term, $R$, appears in the $\varepsilon$-equation. It is closed from an approximation rather than by a rigorous RNG derivation.

\subsection{Model Specifications}

In this study, a commercial CFD software, CONVERGE, was adopted to carry out numerical simulation for the closed part of the engine cycle, namely from IVC (intake valve close) to EVO (exhaust valve open), and the main specifications of the gasoline engine (produced by Chery Automobile Co., Ltd., in China) are shown in Table 1. The computational mesh of the engine geometry is illustrated in Figure 1, and the high-quality orthogonal hexahedral meshes were obtained through CONVERGE codes. In order to keep a tradeoff between computation resolution and efficiency, the AMR strategy was adopted to automatically modify meshes, subject to the distribution of local velocity, temperature and the corresponding species mass fraction [11]. In this study, a basic mesh size of $1 \mathrm{~mm}$ was employed. In addition, one level of invariable boundary embedding was set close to the cylinder head, piston and wall (cell size of $0.6 \mathrm{~mm}$ ), while three levels of invariable spherical embedding (radius of $0.6 \mathrm{~mm}$ ) were carried out to solve the spark (cell size of $0.125 \mathrm{~mm}$ ) [27].

Table 1. Main specifications of the engine.

\begin{tabular}{cc}
\hline Parameters & Value \\
\hline Bore/stroke $(\mathrm{mm})$ & $74.5 / 80$ \\
Number of cylinders & 4 \\
Compression ratio & $10: 1$ \\
Fuel supply method & Direct injection \\
Torque (N.m) & $200(1400 \mathrm{r} / \mathrm{min})$ \\
Rated speed (r/min)/rated power $(\mathrm{kW})$ & $5000 / 90$ \\
\hline
\end{tabular}

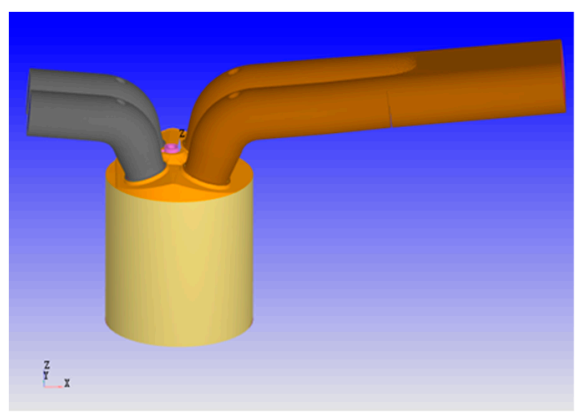

Figure 1. Geometry of the engine.

A lot of parametric conditions were taken into account for initial temperatures and pressures shown in Table 2. The non-uniformity temperature distributions in cylinder were taken into consideration such as cylinder head and piston at $550 \mathrm{~K}$ and $837 \mathrm{~K}$, respectively. The inhomogeneous temperature was characterized by two kinds of initial conditions. Firstly, to describe global temperature variables, a sinusoidal temperature curve was overlayed on the initial average temperature with a specified root-mean-square variation and wavelength spanning the domain length as illustrated in literature [28]. 
In addition, to characterize a local ignition source, a hot spot was represented using a superimposed Gaussian temperature curve [28]. A fuel-air equivalence ratio of 1.05 was set and the mixture was diluted with a certain amount of nitrogen, which ensured not only to serve as an indicator of auto-ignition but also to restrain shock wave coming into being similarly reported in literature [28,29].

Table 2. Boundary conditions and initial conditions.

\begin{tabular}{cc}
\hline Conditions & Value \\
\hline Intake temperature/K & 360 \\
Intake manifold temperature/K & 332 \\
Intake manifold pressure/MPa & 1.8 \\
Cylinder head temperature/K & 550 \\
Cylinder temperature/K & 837 \\
Cylinder wall temperature/K & 475 \\
Piston top temperature/K & 600 \\
Exhaust temperature/K & 550 \\
Exhaust manifold temperature/K & 827 \\
Exhaust manifold pressure/MPa & 1.6 \\
\hline
\end{tabular}

In this study, the working process of the engine was divided into three parts to establish the numerical model, namely the flow process, the spray process and the combustion process. The flow model was used as a preliminary preparation of the combustion model so that the simulations were performed for the intake and compression processes. The simulation calculation period was set in the range from $-366^{\circ} \mathrm{CA}$ to $-20^{\circ} \mathrm{CA}$ and the turbulent model was the RNG $\mathrm{k}-\varepsilon$ turbulent flow model. Since only the flow of air existed during the simulation of the engine gas flow, oxygen and nitrogen were the main components, so only $\mathrm{O}_{2}$ and $\mathrm{N}_{2}$ components needed to be added to the reaction mechanism. The spray process mainly simulated the formation process of fuel spray and air-fuel mixture. It was necessary to add three components of $\mathrm{O}_{2}, \mathrm{~N}_{2}$ and $\mathrm{IC}_{8} \mathrm{H}_{18}$, as well as their thermal physical properties and reaction mechanism. The fuel injection starting point of the six-nozzle injector was $-240{ }^{\circ} \mathrm{CA}$ and the injection duration was $75^{\circ} \mathrm{CA}$. The relevant spray sub-models were shown in Table 3 .

Table 3. Spray model.

\begin{tabular}{cc}
\hline Model Category & Name \\
\hline Turbulent diffusion model & O'Rourke turbulent dispersion model \\
Evaporation model & Frossling model \\
Collision model & NTC (No Time Counter) \\
Fuel drop resistance model & Dynamic drag model \\
Impingement model & Wall film model \\
Broken up model & K-H and R-T \\
\hline
\end{tabular}

The combustion model was established based on the flow model and the spray model. Before the combustion model was established, the flow model and the spray model were calculated to obtain the corresponding results, and the results were then introduced into the combustion model. The SAGE combustion model was selected and the skeletal reaction mechanism of isooctane with 48 species and 152 reactions proposed by Liu et al. [30] was employed rather than detailed reaction kinetics to enhance the computation efficiency. The starting point of the numerical simulation of the combustion model was the end point of the foregoing two models, and the corresponding simulation duration was of $-20^{\circ} \mathrm{CA}$ to $180^{\circ} \mathrm{CA}$. The ignition source item was set according to the L-type ignition energy rule shown in Figure 2. There were two spherical regions with a diameter of $0.75 \mathrm{~mm}$ between the spark plug electrode. Among $-15{ }^{\circ} \mathrm{CA}$ to $-14.5^{\circ} \mathrm{CA}, 0.02 \mathrm{~J}$ of energy was released in the first spherical region. In addition, $0.02 \mathrm{~J}$ of energy was released in the second spherical region among $-14.5^{\circ} \mathrm{CA}$ to $-5^{\circ} \mathrm{CA}$. 


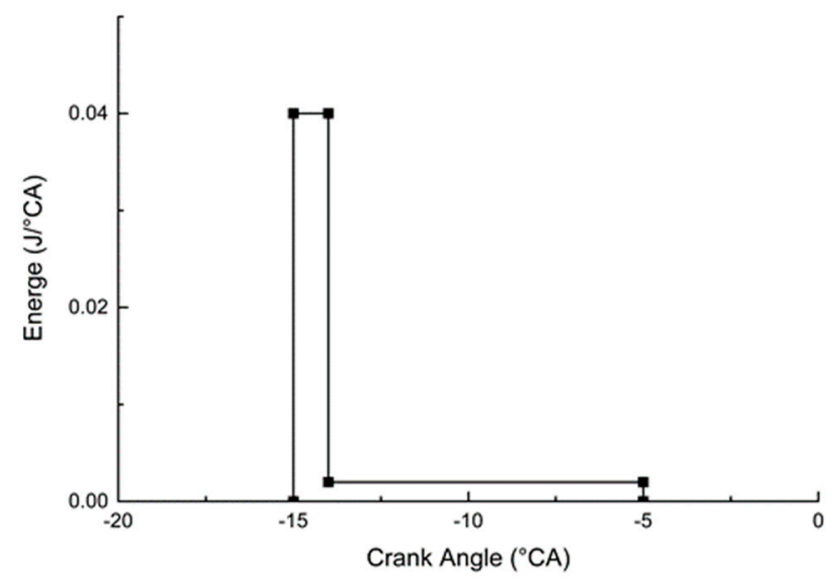

Figure 2. L-type ignition energy.

\section{Results and Discussion}

\subsection{Flow Process Analysis}

In this study, the flow process was simulated to obtain the change of pressure in the cylinder during the flow process. The pressure change is not obvious during the whole intake process, with slight fluctuations. At the beginning of the intake process, because the intake valve is not fully closed, the pressure in the cylinder is close to that of the exhaust port. In the initial stage of intake due to the overlap period of the valve, the pressure in the cylinder fluctuates. Due to the suction of the piston, negative pressure is generated in the cylinder and the pressure is reduced. After the exhaust valve is closed $\left(-315^{\circ} \mathrm{CA}\right)$, the pressure gradually rises again. In the late stage of intake, the pressure continues to rise after $\mathrm{BDC}$ (bottom dead center, $-180^{\circ} \mathrm{CA}$ ) to intake valve closes $\left(-121^{\circ} \mathrm{CA}\right)$ owing to the delayed closing of the intake valve. The lift curves of the intake and exhaust valve are shown in Figure 3.

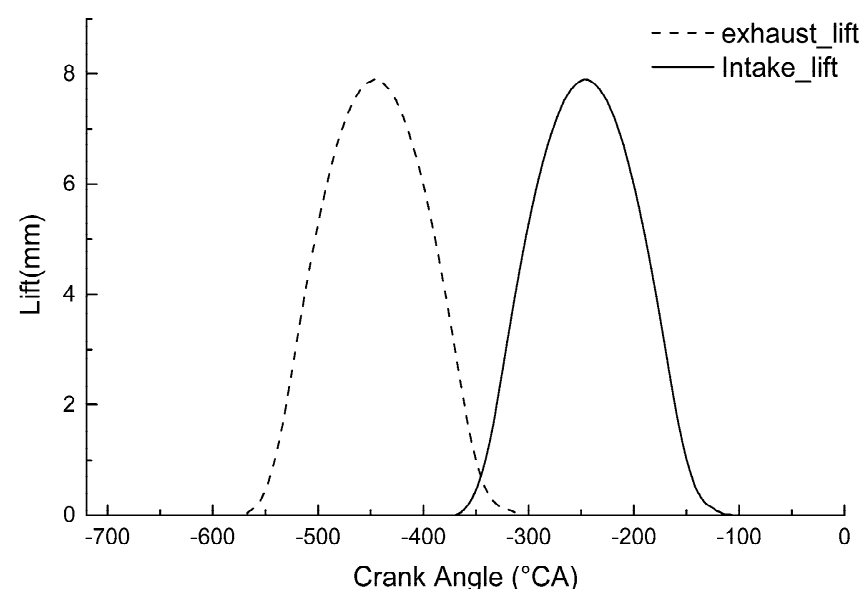

Figure 3. Lift curves of the intake valve and exhaust valve.

Visualizing the flow field of the intake process, as shown in Figure 4, the cut plane is parallel to the center line of the cylinder, and it passes through the center of the valve. The velocity of the air flow value in the calculation result is added to the instantaneous velocity field under different crank angles. After the intake valve is opened, the air in the intake manifold begins to enter the cylinder. In the initial stage of intake, through the analysis of the instantaneous velocity field in the cylinder, it can be observed that a little gas flows back into the intake manifold through the intake valve, which causes the in-cylinder pressure to fluctuate. As the intake valve opening, the air entering the cylinder forms the tumble flow. In the early stage of the intake stroke, there are distinct turbulent motions in two opposite directions around the intake side and exhaust side, respectively. However, the tumble flow 
near the intake side disappears gradually in the compression stroke since the motion of the piston and the valve.
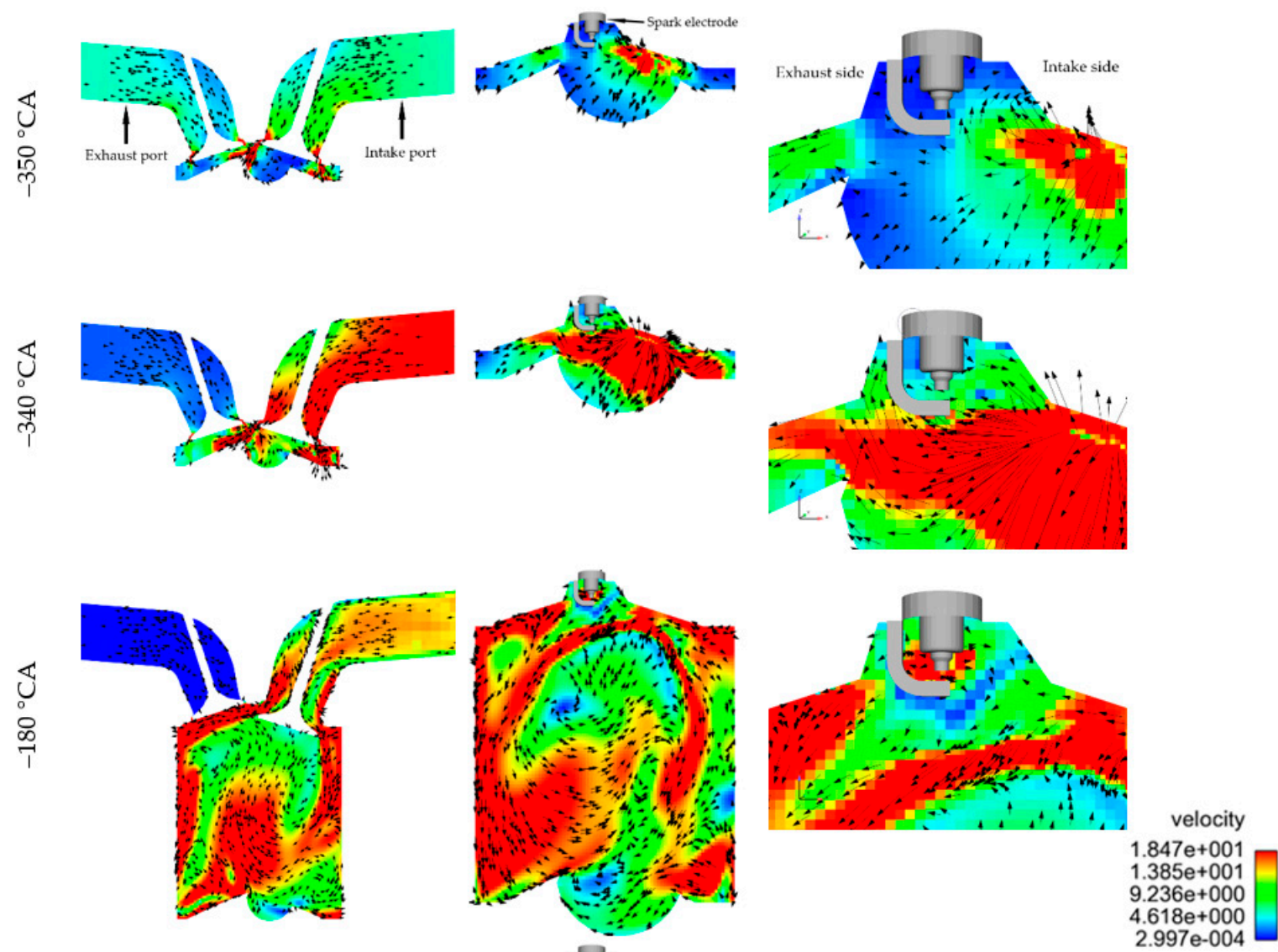

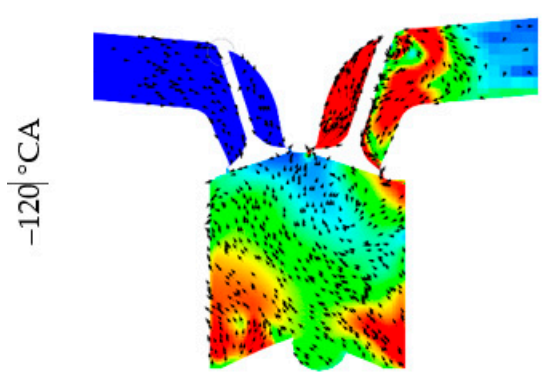

Clip through the center of the valve
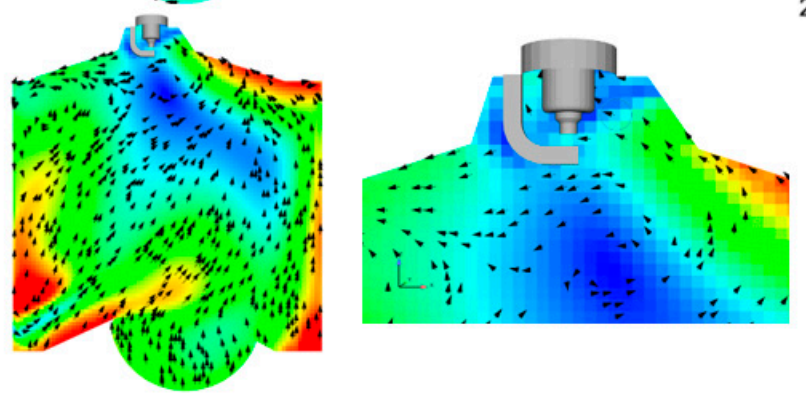

Clip through the center of the spark plug

Figure 4. Instantaneous velocity field of the flow process.

Figure 5 shows the contrast results of tumble ratio during the intake and compression strokes simulated by the G-RNG (generalized renormalization group) $k-\varepsilon$ model and the RNG $k-\varepsilon$ model, respectively. From Figure 5, it can be seen that the tumble ratio in the combustion chamber by the G-RNG $k-\varepsilon$ model had the same trend to that of the RNG $k-\varepsilon$ model similarly reported in literature [31]. As shown in Figure 4, when the intake valves opened, the pressure in the combustion chamber was higher than that in the intake ports, which led to a back flow. As the piston moved down, fresh air began to rush into the combustion chamber and the sign of the tumble ratio varied. After IVO, the tumble motion became more organized due to the piston movement during the compression stroke, leading to a slight increase in the tumble motion, and the tumble of the gas gradually decreased at the end of the compression stroke. 


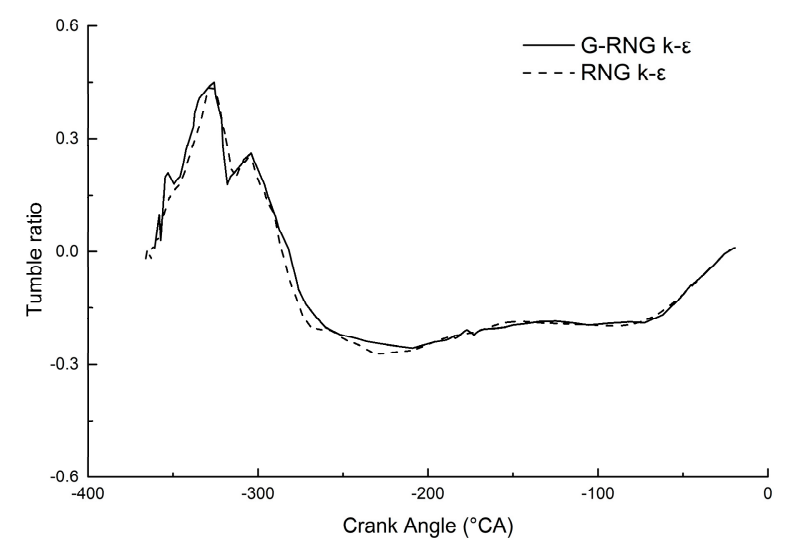

Figure 5. In-cylinder tumble ratio.

\subsection{Spray Process Analysis}

The injector of the engine with six nozzles was installed on the side of intake port and a certain amount of fuel was injected into the cylinder at a certain injection timing. Due to the high temperature and the strong air flow in the cylinder, the fuel was rapidly atomized. The fuel droplets gradually absorbed heat and evaporated during the interaction with the gas in the cylinder. In the early stage of fuel injection, the trajectory of the spray changed significantly. The installation angle of injector was at an angle of $45^{\circ}$ to the cylinder head plane. Figure 6 shows an image of IC8H18 fuel composition cloud diagram and the instantaneous velocity fiefdom the tangent plane parallel to the centerline of the cylinder and passing through the center of the spark plug. It can be seen that the spray trajectory has an obvious shift due to the turbulence caused by spray at $-210{ }^{\circ} \mathrm{CA}$. As illustrated in Figure 6, the installation angle of injector did not adapt to fuel injection advance angle, so most of fuel was injected towards the cylinder liner, which induced the fuel can't mix with the air well. Later the fuel moved to the intake side because of the tumble flow and the swirl flow. It formed the fuel lean region around the exhaust side, therefore the distribution of the fuel was non-uniformly.

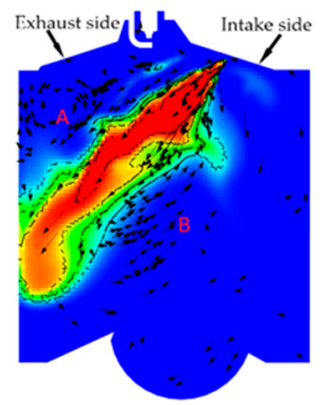

(a) $-210^{\circ} \mathrm{CA}$

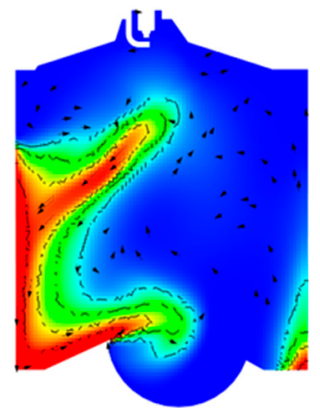

(b) $-155^{\circ} \mathrm{CA}$

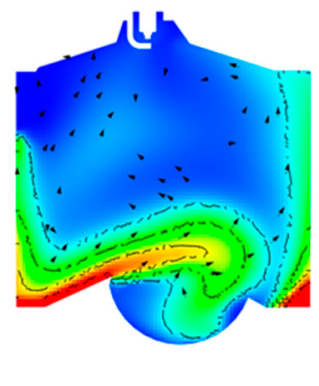

(c) $-110^{\circ} \mathrm{CA}$

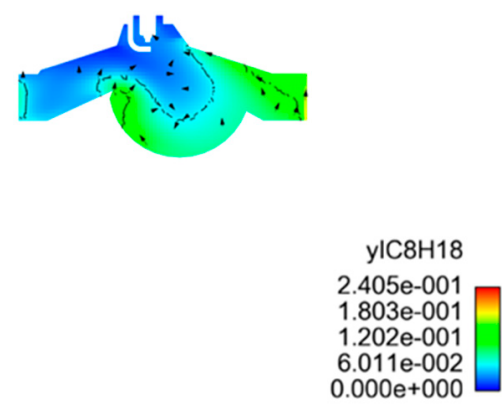

(d) $-30{ }^{\circ} \mathrm{CA}$

Figure 6. $\mathrm{IC}_{8} \mathrm{H}_{18}$ spray cloud and instantaneous velocity field (clip through the spark plug). (a) $-210{ }^{\circ} \mathrm{CA}$; (b) $-155^{\circ} \mathrm{CA}$; (c) $-110^{\circ} \mathrm{CA}$; (d) $-30{ }^{\circ} \mathrm{CA}$.

The counterflow induced by the tumble flow at $-245^{\circ} \mathrm{CA}$ as shown in Figure 7 was retarded at $-240{ }^{\circ} \mathrm{CA}$ since the injection of the fuel. Beside after $-240{ }^{\circ} \mathrm{CA}$ the injection of the fuel caused airflow perturbance and two distinct swirl flow regions were formed at $-235^{\circ} \mathrm{CA}$. After that the above mentioned two swirl flow regions broke up and recombined again. At $-220^{\circ} \mathrm{CA}$ the swirl flow near the cylinder liner could be observed clearly in Figure 7. The tumble flow and the swirl flow were enhanced because of the direct injection, which was able to increase laminar flame speed and the turbulence flame speed at the same time as illustrated in literature [20]. The flow ratio of tumble flow and the swirl flow were induced by fuel direct injection, in addition, tumble flow produced turbulence and increased the turbulent flame speed. 


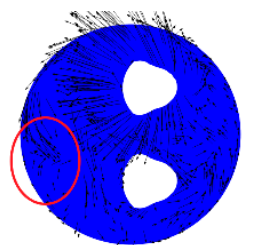

$-245^{\circ} \mathrm{CA}$

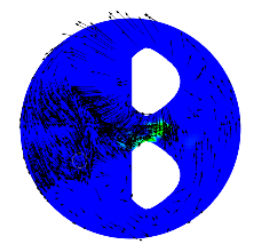

$-215{ }^{\circ} \mathrm{CA}$

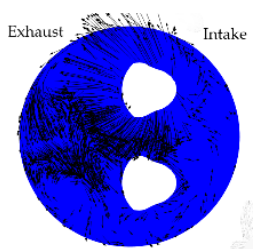

$-240{ }^{\circ} \mathrm{CA}$

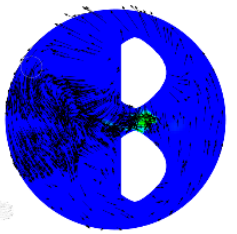

$-210{ }^{\circ} \mathrm{CA}$

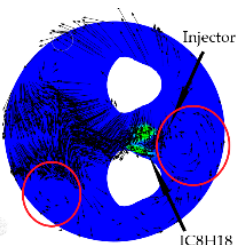

$-235^{\circ} \mathrm{CA}$

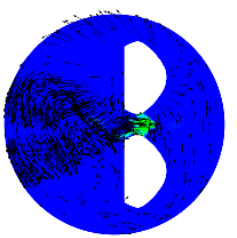

$-205^{\circ} \mathrm{CA}$

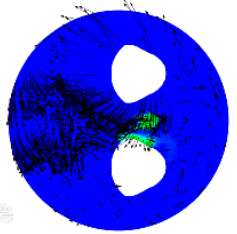

$-230^{\circ} \mathrm{CA}$

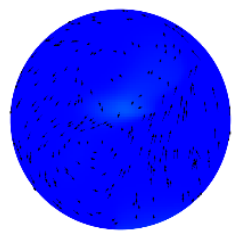

$-155^{\circ} \mathrm{CA}$

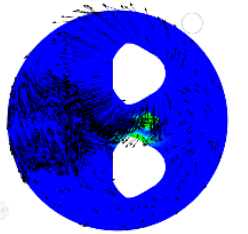

$-225^{\circ} \mathrm{CA}$

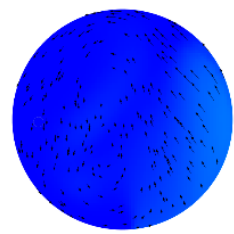

$-110^{\circ} \mathrm{CA}$

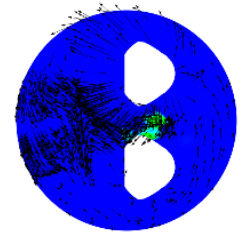

$-220^{\circ} \mathrm{CA}$

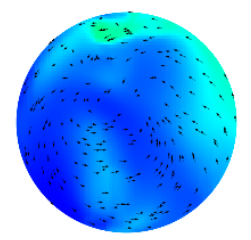

$-30{ }^{\circ} \mathrm{CA}$

$0.000 e+000$

$1.389 e-001$

ylC $8 \mathrm{H} 18$

2.778e-001

4.167e-001

$5.556 \mathrm{e}-001$

Figure 7. $\mathrm{IC}_{8} \mathrm{H}_{18}$ spray cloud and instantaneous velocity field (perpendicular to the centerline of the cylinder and $1 \mathrm{~mm}$ from the top of the head).

At the end of the spray model calculation, the fuel particles did not evaporate completely and the evaporation ratio was $99.13 \%$. Figure 8 shows the equivalence ratio distribution of fuel/air at $-20^{\circ} \mathrm{CA}$. As shown in Figure 8, a fuel lean region was formed because large amounts of fuel were injected towards the spark electrode, and the fuel lean region on the left side was the end-gas region. A fuel lean region was produced, and the knock propensity in this region was totally suppressed by longer ignition delay time of the fuel lean condition. Nevertheless, by analyzing the distribution and the percentage of equivalence ratio, it could also be seen that the fuel and air distribution was relatively dispersed at the $-20^{\circ} \mathrm{CA}$, and a certain of fuel was attached to the cylinder wall.

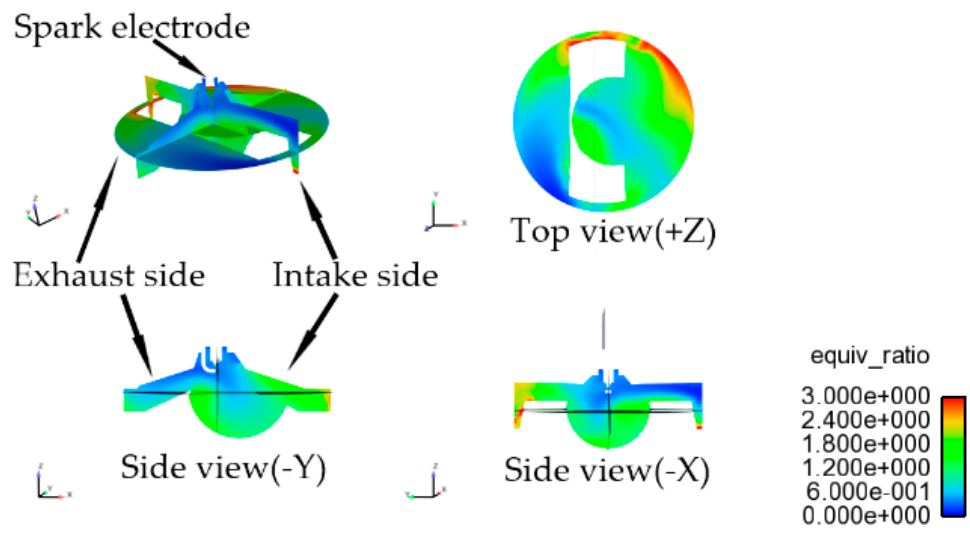

Figure 8. Equivalence ratio of fuel/air at $-20^{\circ} \mathrm{CA}$.

\subsection{Combustion Process Analysis}

\subsubsection{Normal Combustion Process Analysis}

In the normal combustion process, the engine speed was $3000 \mathrm{r} / \mathrm{min}$, and the ignition timing was $-15^{\circ} \mathrm{CA}$. The variation of in-cylinder pressure during normal combustion is shown by the solid line in Figure 9. After the mixture was ignited, the flame front began to gradually spread around. The temperature value of $2300 \mathrm{~K}$ in the combustion process was selected to establish the temperature isosurface in the three-dimensional space to simulate the flame propagation process, as shown in Figure 10. Combining with the results of the spray calculation, it can be found that since the fuel was mainly distributed on the intake side, and most of the mixture equivalence ratio was near to 1.05 , it was 
favorable for rapid combustion, so that the flame propagated faster on the intake side. By analyzing the temperature field and the process of flame propagation, it can be found that the flame front had already swept through the entire combustion chamber around $20^{\circ} \mathrm{CA}$.

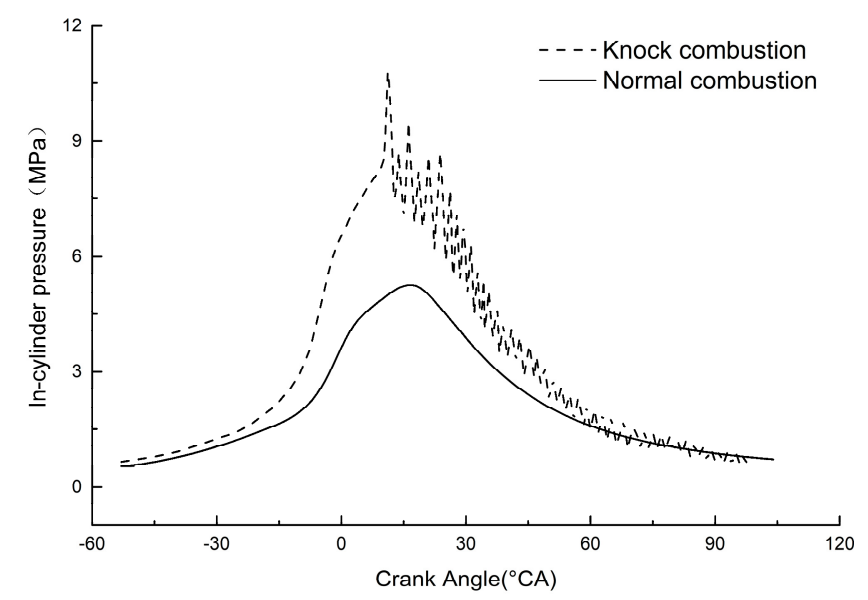

Figure 9. In-cylinder pressure of normal combustion and knock combustion.

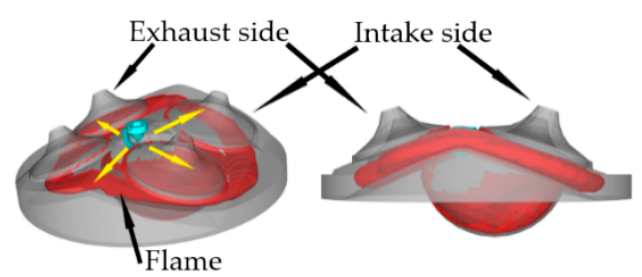

(a) $4{ }^{\circ} \mathrm{CA}$

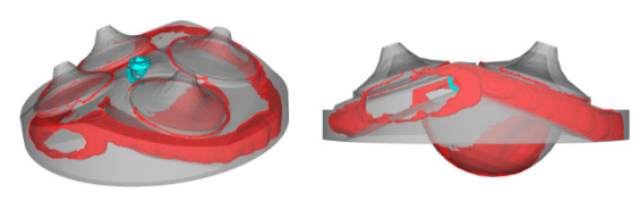

(c) $14^{\circ} \mathrm{CA}$
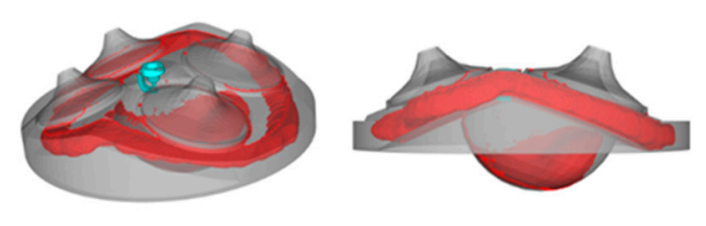

(b) $9{ }^{\circ} \mathrm{CA}$

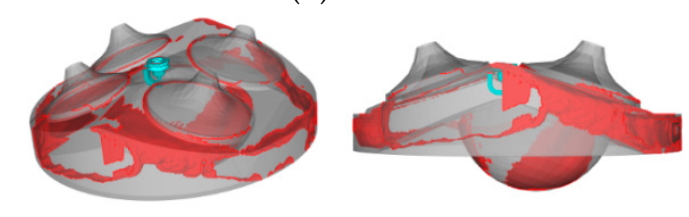

(d) $19{ }^{\circ} \mathrm{CA}$

Figure 10. Flame propagation of normal combustion (Intake port on the right).

\subsubsection{Knock Combustion Process Analysis}

In this simulation the engine operates with a full load, which means the amount of injection was a maximum of $5.16155 \times 10^{-5} \mathrm{~kg}$. Figure 9 also shows the comparison of the in-cylinder pressure during knock combustion and normal combustion. It can be observed from the Figure 9 that the ascending rate of in-cylinder pressure during knock combustion was greater than that of normal combustion. The present simulation could capture the correct amplitude of pressure oscillations generated by a knock, due to the use of a compressible code and an accurate auto-ignition heat release rate model shown in Figure 11. It can be seen from Figure 11 that there were two obvious pressure peaks. This phenomenon was due to the fact that the thermodynamic state of the end-mixture reached a state of auto-ignition as illustrated in literature [32,33]. Under the compression and heating of the flame front, the instantaneous heat release created a tremendous pressure wave, which led to a sharp rise in cylinder pressure. Auto-ignition mainly started in the half of the cylinder located under the exhaust valves, which was illustrated by their higher temperature compared to intake ones. Such a location was observed experimentally in the literature [34], and was explained by the larger residence time of fresh gases there (the flame tended to burn fresh gases more rapidly on the exhaust side due to the tumble motion) [10]. Figures 12 and 13 show the process of the flame propagation and temperature cloud during the knock combustion, respectively. At $14{ }^{\circ} \mathrm{CA}$, an auto-ignition point 
is formed near the exhaust valve, and the flame gradually spreads around. Due to the limitation of the computer hardware, the output frequency of the selected $3 \mathrm{D}$ results is a result output per $5{ }^{\circ} \mathrm{CA}$. Combined with the related findings, it can be concluded that the propagating detonation wave derived from multiple hot-spots auto-ignition indicates vital effects on knock intensity of in-cylinder pressure at $24^{\circ} \mathrm{CA}$, which is consistent with the research findings [11,12].

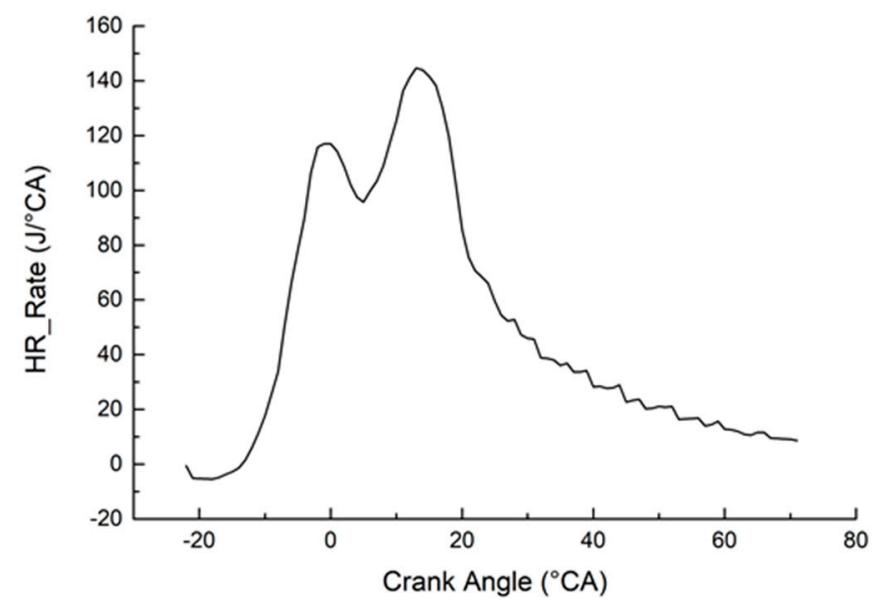

Figure 11. Heat release rate of knock combustion.

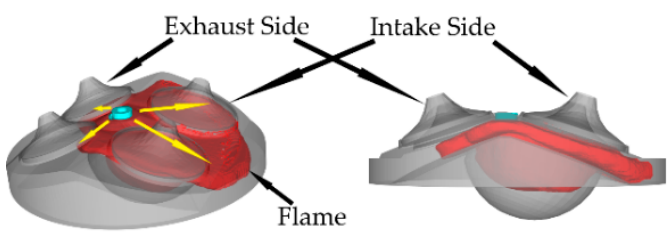

(a) $9{ }^{\circ} \mathrm{CA}$
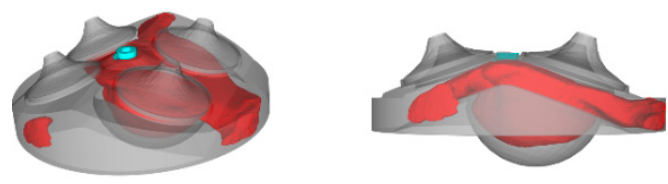

(c) $19^{\circ} \mathrm{CA}$

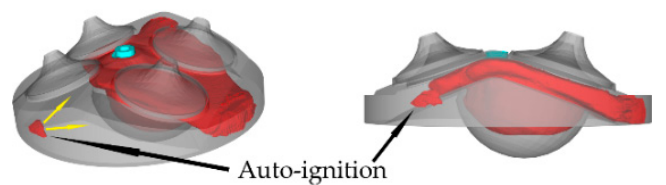

(b) $14{ }^{\circ} \mathrm{CA}$
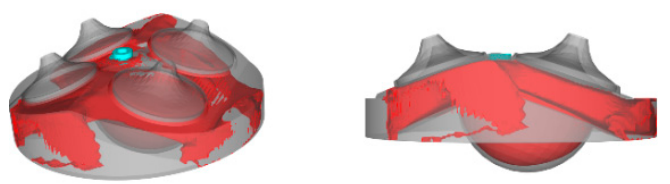

(d) $24^{\circ} \mathrm{CA}$

Figure 12. Flame propagation of knock combustion (intake port on the right).

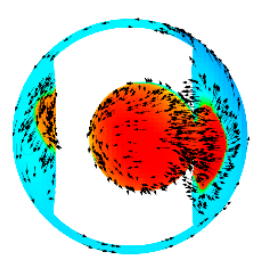

$4{ }^{\circ} \mathrm{CA}$

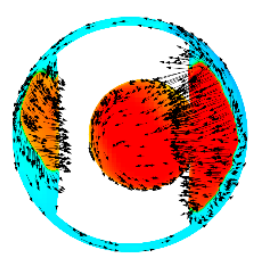

$9{ }^{\circ} \mathrm{CA}$

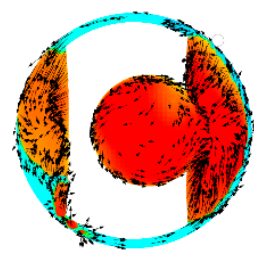

$14^{\circ} \mathrm{CA}$

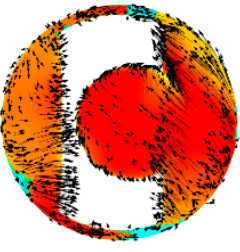

$19^{\circ} \mathrm{CA}$

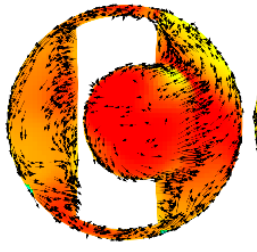

$24^{\circ} \mathrm{CA}$

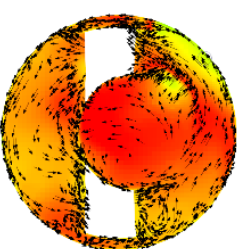

$29^{\circ} \mathrm{CA}$

$3.600 \mathrm{e}+002$ $9.700 e+002$

temp $1.580 \mathrm{e}+003$ $2.190 e+003$ $2.800 e+003$

Figure 13. Temperature cloud and instantaneous velocity field (top view).

\section{Conclusions}

In this study, software CONVERGE was used to numerically model the gas flow, spray process and combustion process of a supercharged gasoline direct injection engine under practical engine 
operating conditions. For combustion modeling, the normal combustion and knock combustion were analyzed, respectively. The conclusions could be drawn as follows:

(1) During the gas flow process, the tumble in the cylinder was gradually formed with the increase of the valve lift, enhanced in the compression stroke and finally was broken due to the extrusion of the piston. The tumble ratio in the combustion chamber by the G-RNG $k-\varepsilon$ model had the same trend to that of the RNG $k-\varepsilon$ model.

(2) During the spray process, the results show that the fuel droplets gradually evaporated and moved to the intake side under the turbulent and high temperature in the cylinder. Nevertheless, fuel and air distribution was relatively dispersed at the $-20^{\circ} \mathrm{CA}$, and a certain amount of fuel was attached to the cylinder wall.

(3) During the normal combustion process, most of the mixture equivalence ratio was near to 1.05 , it was favorable for rapid combustion, so that the flame propagated faster on the intake side. During the knock combustion process, the correct amplitude of pressure oscillations generated by a knock could be captured. At $14{ }^{\circ} \mathrm{CA}$, an auto-ignition point was formed near the exhaust valve, and the flame gradually spread around. Combined with the related findings, it could be concluded that the propagating detonation wave derived from multiple hot-spots auto-ignition indicated vital effects on knock intensity of in-cylinder pressure at $24^{\circ} \mathrm{CA}$.

Author Contributions: X.W., X.Z. and H.C. conceived and developed the paper; X.Z. conducted the simulation and the draft; M.W. conducted the typesetting of the paper; Y.H. provided guidance and reviews throughout the development of this paper.

Funding: This research is funded by "State Key Laboratory of Engines at Tianjin University (K2018-09)", "Research Center of Manufacturing Development of Wuhan City Circle (WZ2016Y15)" and "Research fund of Center for Materials Research and Analysis, WHUT (2018KFJJ07)".

Acknowledgments: The authors would like to thank CSSC Huangpu Wenchong Shipbuilding Company Limited for financial support.

Conflicts of Interest: The authors declare no conflict of interest.

\section{References}

1. Robert, A.; Richard, S.; Colin, O.; Poinsot, T. LES study of deflagration to detonation mechanisms in a downsized spark ignition engine. Combust. Flame 2015, 162, 2788-2807. [CrossRef]

2. Zhen, X.; Wang, Y.; Xu, S.; Zhu, Y.; Tao, C.; Xu, T.; Song, M. The engine knock analysis-An overview. Appl. Energy 2012, 92, 628-636. [CrossRef]

3. Yu, H.; Chen, Z. End-gas autoignition and detonation development in a closed chamber. Combust. Flame 2015, 162, 4102-4111. [CrossRef]

4. Bradley, D.; Kalghatgi, G.T. Influence of autoignition delay time characteristics of different fuels on pressure waves and knock in reciprocating engines. Combust. Flame 2009, 156, 2307-2318. [CrossRef]

5. Wang, Z.; Liu, H.; Song, T.; Qi, Y.; He, X.; Shuai, S.; Wang, J. Relationship between super-knock and pre-ignition. Int. J. Engine Res. 2015, 16, 166-180. [CrossRef]

6. Kalghatgi, G.T. Developments in internal combustion engines and implications for combustion science and future transport fuels. Proc. Combust. Inst. 2015, 35, 101-115. [CrossRef]

7. Yao, A.; Xu, H.; Yao, C. Analysis of pressure waves in the cone-type combustion chamber under SI engine knock. Energy Convers. Manag. 2015, 96, 146-158. [CrossRef]

8. Mittal, V.; Revier, B.M.; Heywood, J.B. Phenomena that determine knock onset in spark-ignition engines. SAE Pap. 2007, 2007-01-0007. [CrossRef]

9. Marseglia, G.; Costa, M.; Catapano, F.; Sementa, P.; Vaglieco, B.M. Study about the link between injection strategy and knock onset in an optically accessible multi-cylinder GDI engine. Energy Convers. Manag. 2017, 134, 1-19. [CrossRef]

10. Robert, A.; Richard, S.; Colin, O.; Martinez, L.; de Francqueville, L. LES prediction and analysis of knocking combustion in a spark ignition engine. Proc. Combust. Inst. 2015, 35, 2941-2948. [CrossRef]

11. Pan, J.; Wei, H.; Shu, G.; Pan, M.; Feng, D.; Li, N. LES analysis for auto-ignition induced abnormal combustion based on a downsized SI engine. Appl. Energy 2017, 191, 183-192. [CrossRef] 
12. Wang, Z.; Qi, Y.; He, X.; Wang, J.; Shuai, S.; Law, C.K. Analysis of pre-ignition to super-knock: Hotspot-induced deflagration to detonation. Fuel 2015, 144, 222-227. [CrossRef]

13. Park, S.; Woo, S.; Oh, H.; Lee, K. Effects of various lubricants and fuels on pre-ignition in a turbocharged direct-injection spark-ignition engine. Energy Fuels 2017, 31, 12701-12711. [CrossRef]

14. Wang, Z.; Liu, H.; Rolf, R.D. Knocking combustion in spark-ignition engines. Prog. Energy Combust. Sci. 2017, 61, 78-112. [CrossRef]

15. Okada, Y.; Miyashita, S.; Izumi, Y.; Hayakawa, Y. Study of low-speed pre-ignition in boosted spark ignition engine. SAE Int. J. Engines 2014, 7, 584-594. [CrossRef]

16. Dahnz, C.; Han, K.-M.; Spicher, U.; Magar, M. Investigations on pre-ignition in highly supercharged SI engines. SAE Int. J. Engines 2010, 3, 214-224. [CrossRef]

17. Dahnz, C.; Spicher, U. Irregular combustion in supercharged spark ignition engines pre-ignition and other phenomena. Int. J. Engine Res. 2010, 11, 485-498. [CrossRef]

18. Kalghatgi, G.T.; Bradley, D. Pre-ignition and 'super-knock' in turbo-charged spark-ignition engines. Int. J. Engine Res. 2012, 13, 399-414. [CrossRef]

19. Zhen, X.; Wang, Y.; Zhu, Y. Study of knock in a high compression ratio SI methanol engine using LES with detailed chemical kinetics. Energy Convers. Manag. 2013, 75, 523-531. [CrossRef]

20. Shao, J.; Rutland, C.J. Modeling investigation of different methods to suppress engine knock on a small spark ignition engine. J. Eng. Gas Turbines Power 2015, 137, 061506-061520. [CrossRef]

21. Teraji, A.; Kakuho, A.; Tsuda, T.; Hashizume, Y. A study of the knocking mechanism in terms of flame propagation behavior based on 3D numerical simulations. SAE Int. J. Engines 2009, 2, 666-673. [CrossRef]

22. Senecal, P.; Pomraning, E.; Richards, K.J.; Briggs, T.E. Multi-dimensional modeling of direct injection diesel spray liquid length and flame lift-off length using CFD and parallel detailed chemistry. SAE Pap. 2003, 2003-01-1043. [CrossRef]

23. Richards, K.J.; Senecal, P.K.; Pomraning, E. CONVERGE Users Guide E Reference Manual (Version 2.3.0); Convergent Science: Middleton, WI, USA, 2016.

24. Turns, S.R. An Introduction to Combustion; McGraw-Hill, Inc.: New York, NY, USA, 1996.

25. Han, Z.; Reitz, R.D. Turbulence modeling of internal combustion engines using RNG $\kappa-\varepsilon$ models. Combust. Sci. Technol. 1995, 106, 267-295. [CrossRef]

26. Wang, F.; Reitz, R.D.; Pera, C.; Wang, Z.; Wang, J. Application of generalized RNG turbulence model to flow in motored single-cylinder PFI engine. Eng. Appl. Comput. Fluid Mech. 2013, 7, 486-495. [CrossRef]

27. Pal, P.; Wu, Y.; Lu, T.; Som, S.; See, Y.C.; Moine, A.L. Multidimensional numerical simulations of knocking combustion in a cooperative fuel research engine. J. Energy Resour. Technol. 2018, 140, 102205. [CrossRef]

28. Pal, P.; Mansfield, A.B.; Arias, P.G.; Wooldridge, M.S.; Im, H.G. A computational study of syngas auto-ignition characteristics at high-pressure and low-temperature conditions with thermal inhomogeneities. Combust. Theory Model. 2015, 19, 587-601. [CrossRef]

29. Gu, X.J.; Emerson, D.R.; Bradley, D. Modes of reaction front propagation from hot spots. Combust. Flame 2003, 133, 63-74. [CrossRef]

30. Liu, Y.; Jia, M.; Xie, M.; Pang, B. Enhancement on a skeletal kinetic model for primary reference fuel oxidation by using a semidecoupling methodology. Energy Fuels 2012, 26, 7069-7083. [CrossRef]

31. Wang, F. Multidimensional Numerical Simulation of Flame Propagation and Knock Combustion in Turbocharged Gasoline Direct Injection Engine. Ph.D. Thesis, Tsinghua University, Beijing, China, 2015; pp. 36-55.

32. Qi, Y.; Wang, Z.; Wang, J.; He, X. Effects of thermodynamic conditions on the end gas combustion mode associated with engine knock. Combust. Flame 2015, 162, 4119-4128. [CrossRef]

33. Zahdeh, A.; Rothenberger, P.; Nguyen, W.; Anbarasu, M. Fundamental approach to investigate pre-ignition in boosted SI engines. SAE Int. J. Engines 2011, 4, 246-273. [CrossRef]

34. Hettinger, A.; Kulzer, A.; Spicher, U. Higher specific load-Increasing knock risk evaluation of measures for knock reduction using multiple pressure indication. In Proceedings of the 9th International Symposium on Combustion Diagnostics 2010, Kurhaus Baden-Baden, Germany, 8-9 June 2010.

(C) 2019 by the authors. Licensee MDPI, Basel, Switzerland. This article is an open access article distributed under the terms and conditions of the Creative Commons Attribution (CC BY) license (http://creativecommons.org/licenses/by/4.0/). 